\title{
OMBUDSMAN OU OUVIDOR: DEFENSOR DOS DIREITOS DA POPULAÇÃO NA FISCALIZAÇÃO DA ADMINISTRAÇÃO PÚBLICA
}

OMBUDSMAN: ADVOCATE OF PEOPLE RIGHTS IN THE INSPECTION OF PUBLIC ADMINISTRATION

JOSÉ ANTÔNIO REMÉDIO ${ }^{1}$

TAMIRES GOMES DA SILVA CASTIGLIONI ${ }^{2}$

\section{RESUMO}

A pesquisa tem por objeto analisar o instituto do Ombudsman ou Ouvidor como defensor dos direitos da população na fiscalização da Administração Pública e guardião da legalidade contra a improbidade e os abusos de poder no exercício da atividade administrativa. Com a Constituição Federal de 1988 o Brasil retomou o caminho tradicional da Democracia e do Estado de Direito. Todavia, apesar do clima democrático instaurado, a Assembleia Nacional Constituinte rejeitou a proposta que instituiria a figura do Ombudsman no País. O método adotado é o hipotético-dedutivo, com base na legislação, doutrina e jurisprudência. Conclui que o Ombudsman ou a Ouvidoria, como órgão externo da Administração Pública, embora não esteja previsto expressamente na Lei Maior, tem a missão de fiscalizar de forma imparcial a Administração Pública, em defesa dos direitos fundamentais, à luz da Constituição Federal e dos princípios e normas que regem o Estado Democrático de Direito Brasileiro.

Palavras-chave: Administração Pública. Defensor dos Direitos da População. Fiscalização da Administração Pública. Ombudsman. Ouvidoria.

\section{ABSTRACT}

The research aims to analyze the Ombudsman institute as an advocate for the rights of the population to supervise the Public Administration and as a guardian of legality against impropriety and abuses of power in the exercise of administrative activity. With the Federal Constitution of 1988, Brazil resumed the traditional way of Democracy and Rule of Law. However, despite the democratic climate established, the National Constituent Assembly rejected the proposal that would establish the figure of the Ombudsman in the country. The method used is the hypothetical-deductive, based on legislation, doctrine and jurisprudence. It is

1 Pós-Doutorando em Direito pela Universidade Estadual do Norte do Paraná (UENP). Doutor em Direito do Estado pela Pontifícia Universidade Católica de São Paulo (PUCSP). Mestre em Direito Constitucional pela Universidade Metodista de Piracicaba (UNIMEP). Professor de Graduação e Pós-Graduação em Direito da Universidade Metodista de Piracicaba (UNIMEP). Professor de Graduação em Direito do Centro Universitário Adventista de Engenheiro Coelho (UNASP). Promotor de Justiça do Estado de São Paulo Aposentado. Advogado. jaremedio@yahoo.com.br

2 Mestranda em Direito pela Universidade Metodista de Piracicaba, UNIMEP/SP. Bacharel em Ciências Contábeis pelo Centro Universitário Adventista de São Paulo (UNASP). Graduanda em Direito pelo Centro Universitário Adventista de São Paulo (UNASP). tami.ja@hotmail.com 
concluded that the Ombudsman, as an external body of the Public Administration, although not expressly provided in the Major Law, has the mission of impartial inspection of Public Administration in defense of fundamental rights, all in light of the Federal Constitution and the principles and norms that govern the Brazilian Democratic State of Law.

Keywords: Public administration. Advocate of people rights. Fiscalization of public administration. Ombudsman.

\section{INTRODUÇÃO}

O Estado Democrático de Direito é indissociável do exercício dos direitos individuais e coletivos e, para que haja sua preservação, inclusive no mundo globalizado, é necessário o estabelecimento de mecanismos que concretizem e materializem esses direitos.

Os Estados, na atualidade, "não se limitam a garantir os direitos mínimos aos indivíduos, mas também atuam na promoção de implementação dos direitos fundamentais individuais, sociais e coletivos" (REMEDIO; FARIA, 2019, p. 723).

Entre os instrumentos existentes à disposição do cidadão, objetivando a proteção e implementação dos direitos fundamentais, destacam-se o Ombudsman e as Ouvidorias, normalmente utilizados no controle das atividades da Administração Pública, embora também possam ser usados em relação às atividades privadas.

O Ombudsman surgiu há quase dois séculos na Suécia, como parte integrante do controle da administração da res publica, e ganhou ampla aceitação, sobretudo após a segunda Guerra Mundial, como mecanismo de democracia e fiscalização da Administração Pública.

De acordo com a Associação Brasileira de Ouvidores/Ombudsman de São Paulo, há ouvidores em vários países, com nomenclaturas diferentes, mas com atribuições semelhantes, como o provedor da justiça em Portugal, o defensor del pueblo nas nações de língua hispânica, o meditér de la republique nos países de língua francesa, o procurador de los derechos humanos na Guatemala (ABO SÃO PAULO, s.d.).

Ombudsman é uma palavra sueca que significa representante do cidadão, é o mesmo que ouvidor. Nos países escandinavos Ombudsman designa o Ouvidor-Geral, com "função pública criada para canalizar problemas e reclamações da população" (UNIVERSIDADE, s.d.).

O Brasil, com a Constituição Federal de 1988, retomou o caminho da democracia e do Estado de Direito, após longo período de exceção iniciado em 1964. No entanto, apesar do clima democrático instaurado no País, a Assembleia Nacional Constituinte rejeitou a Proposta de Emenda que instituiria expressamente na Constituição Federal a figura do Ombudsman ou Defensor do Povo.

A Constituição de 1988 descentralizou a Ouvidoria, sendo que qualquer Poder Executivo pode, por lei ou decreto, estabelecer a sua Ouvidoria, de forma que o Ouvidor passou a ser representante direto do cidadão, ou seja, é o defensor do cidadão, com identificação do bom ou do mau serviço do órgão público (SÃO PAULO, s.d.).

Para se ter uma ideia de sua dimensão, no Estado de São Paulo, somente considerando-se a área pública, há cerca de 165 ouvidorias, sendo 26 entre as concessionárias de servi- 
ços públicos. Ao mesmo tempo, inúmeras empresas privadas perceberam a necessidade de avançarem além dos serviços básicos de atendimento ao consumidor e também passaram a se utilizar da Ouvidoria/Ombudsman (SÃO PAULO, s.d.).

$\mathrm{Na}$ iniciativa privada brasileira, o cargo de Ombudsman foi criado em 1986 pelo Jornal Folha de São Paulo, sendo exercido por um profissional dedicado a, entre outras atividades, receber, investigar e encaminhar as queixas dos leitores e realizar a crítica interna do jornal, profissional esse que não podia ser demitido durante o mandato respectivo (UNIVERSIDADE, s.d.).

$\mathrm{Na}$ atualidade, o ombudsman corresponde a um instrumento que possibilita a participação popular no controle da ação governamental, assim contribuindo para o exercício da cidadania.

A pesquisa busca analisar o instituto do Ombudsman, às vezes também intitulado Provedor de Justiça, Defensor do Povo ou Ouvidor, sob a ótica de ser um dos guardiões da legalidade em defesa dos cidadãos e contra a improbidade e os abusos praticados pela Administração Pública no exercício de suas funções, bem como sua trajetória histórica, importância, âmbito de atuação e aplicação no ordenamento jurídico brasileiro.

Embora inexista uniformidade de pensamento a respeito, a maioria dos autores, conforme referência de Wanderley Batista Silva (s.d.), procurador de Justiça e Ouvidor-Geral do Ministério Público do Paraná, assim como ocorre com Gustavo Costa Nassif (2010), não distingue entre Ombudsman e Ouvidor, entendimento esse adotado na elaboração da presente pesquisa.

Dentre as atuações do Ombudsman, uma das mais importantes é o auxílio dado aos cidadãos em suas relações com o Estado, representando um elo entre o povo e a Administração Pública. Vale ressaltar que o Ministério Público Brasileiro tem operado com ênfase em defesa do patrimônio público, por ato de improbidade administrativa e ações penais em desfavor de gestores e administradores públicos, atuando em relação a essas atividades como verdadeira espécie de Ombudsman.

De outro lado, há de merecer destaque a atuação individualizada do Ombudsman como defensor imparcial do povo, que luta pela defesa de direitos fundamentais e pelo controle da atividade pública.

É indispensável a figura do Ombudsman no Estado Democrático de Direito, visto que o sistema político deve garantir a participação dos cidadãos na Administração Pública, sendo que o defensor do povo não veio substituir os meios contenciosos, administrativos e políticos de solução de conflitos, mas contribuir para suprir a deficiência de tais meios.

Em 1995 foi criada a Associação Brasileira de Ouvidores/Ombudsman, com a finalidade inicial de "estimular a implantação de novas Ouvidorias (públicas e privadas) com fundamentos escoimados na defesa dos direitos do cidadão". Sua atuação foi ampliada, por compreender que na ideia subjacente ao Ombudsman "estava a promoção da cidadania, da participação social nos destinos do Estado e suas concessões como a forma mais legítima de controle e fiscalização" (NASSIF, 2010).

No tocante à estrutura, a pesquisa se inicia com a análise do surgimento e história do Ombudsman, em seguida foca o conceito e a importância do instituto, a seguir trata de seu 
âmbito de atuação, na sequência pondera sobre a possibilidade de sua implantação no Brasil, a seguir aborda sua relação com o Tribunal de Contas da União, o Poder Executivo, o Ministério Público e o Poder Judiciário.

O método utilizado é o hipotético-dedutivo, com base na legislação, doutrina e jurisprudência.

Tem-se, como hipótese, que o Ombudsman ou a Ouvidoria, como órgão externo da Administração, tem a missão de fiscalizar de forma imparcial a Administração Pública em defesa dos direitos fundamentais, à luz da Constituição Federal e dos princípios e regras que regem o Estado de Direito Brasileiro.

\section{SURGIMENTO E HISTÓRIA DO OMBUDSMAN}

O Ombudsman apareceu pela primeira vez na Suécia, em $1809^{3}$, período em que o rei Gustavo Adolfo foi destronado e o papel do Ombudsman entrou em ação para fiscalizar os órgãos da Administração Pública (NAPIONE, 1969).

A Finlândia foi o segundo país a adotar a figura do Ombudsman, com o intervalo de mais de cem anos em relação ao seu antecessor sueco. O país viveu sob o domínio sueco até 1809, em decorrência das guerras napoleônicas. Até 1917 a Finlândia era governada por um Governador-Geral indicado pelo Imperador, o que impossibilitava a implantação do Ombudsman. Foi somente no governo de Karlo Castrén, em julho de 1919, que se introduziu o papel do Ombudsman na Finlândia (AMARAL FILHO, 1993, p. 44).

$\mathrm{Na}$ Noruega, em 1912, houve uma restruturação das Forças Armadas, estabelecendo-se a criação de órgãos representativos. Contudo, a função da estrutura organizacional autoritária das Forças Armadas foi se tornando cada vez mais complexa, pois sempre a última voz sobre qualquer assunto de interesse de um soldado estava condicionada à boa vontade de suas autoridades superiores. Em 1946 foi criada uma comissão especial para averiguar o funcionamento da administração militar e seu sistema de representação. Marcos Jordão Teixeira de Amaral Filho (1993, p. 63) afirma que essa comissão passou a eleger o Ombudsman, com o papel de conhecer as queixas dos recrutas ou de oficiais, conhecer assuntos por iniciativa própria, atuar como órgão assessor das principais autoridades militares e civis e manter estreito contato com as comissões de representantes.

Na Alemanha a criação do Ombudsman foi proposta em 1952 pelo deputado Ernst Paul, do Partido Social-Democrata, que esteve exilado na Suécia durante o período nazista. Todavia, apenas cinco anos depois, em 1957, foi aprovada a lei constitucional, chamada Lei do Ombudsman Militar Alemão, com o intuito de fiscalizar os fatos que viessem a violar os direitos fundamentais dos soldados (FONSECA, 2000).

A Dinamarca, com o fim da Segunda Guerra Mundial, sentiu também a necessidade de ampliação das garantias individuais contra os abusos do Estado. Assim, no dia 11 de setem-

3 O berço do Ombudsman, para Walter Gellhorn (1966, p. 194), é Constituição Sueca de 1809, que se baseou na teoria de Montesquieu para dividir o poder Executivo, o Parlamento e os Tribunais, e assim supervisionar o cumprimento de seus deveres oficiais. 
bro de 1954 foi promulgada a Lei do Ombudsman, complementada por Instruções do Parlamento em 22 de março de 1956 (FONSECA, 2000).

Na Grã-Bretanha o Ombudsman foi criado em 1964, seguindo os moldes da Suécia e dos países nórdicos, para controle da administração do Reino Unido (VENTURA, 2008). Tinha competência para investigar os casos de má administração provenientes de atividades meramente executivas do governo (AMARAL FILHO, 1993, p. 88).

Nos Estados Unidos, apesar da apresentação de projetos no sentido da criação de um Ombudsman, a proposta não progrediu, e a experiência americana ficou restrita a alguns Estados, como Havaí em 1967, Nebraska em 1969, lowa em 1972, New Jersy em 1974 e Alasca em 1975 (FONSECA, 2000).

Em Portugal, com a Revolução dos Cravos, de 25 de abril de 1974, junto às transformações democráticas exigidas pela sociedade portuguesa, introduziu-se um Ombudsman, chamado de provedor de justiça. Ele atua como oficial ou mediador, recebendo queixas contra qualquer funcionário administrativo, visando a correção dos erros e atos administrativos ilegais e a melhoria dos serviços (AMARAL FILHO, 1993, p. 106). A instituição do Ombudsman tornou-se indispensável em Portugal, no propósito de prevenir e de promover a defesa dos direitos em geral e das liberdades públicas e particulares (VENTURA, 2008, p. 5).

No Brasil, embora não exista formalmente o Ombudsman, uma figura similar surgiu em 1823, em projeto constituinte de José de Souza Mello, que criou o Juízo do Povo, para que a população pudesse reclamar de opressões e injustiças perante a Corte.

A primeira experiência brasileira concreta deu-se em 1986, com a criação da Ouvidoria- Geral do Município de Curitiba, com a finalidade de atuar na defesa dos direitos individuais e coletivos contra atos e omissões ilegais cometidos pela Administração Pública Municipal. Em 2007 foi criada a Ouvidoria-Geral do Ministério Público do Estado do Paraná, por meio da Lei Complementar Estadual n. 117/2007, tendo por objetivo contribuir para elevar os padrões de transparência, presteza e segurança das atividades dos membros, órgãos e serviços auxiliares da Instituição (SILVA, s.d.).

A Lei Federal 13.460/2017, que dispõe sobre participação, proteção e defesa dos direitos o usuário dos serviços públicos da Administração Pública direta e indireta da União, dos Estados, do Distrito Federal e dos Municípios, nos termos do inciso I do $\S 3^{\circ}$ do art. 37 da Constituição Federal, estatui que o usuário poderá apresentar manifestações perante a Administração Pública a respeito da prestação de serviços públicos (art. $9^{\circ}$ ), a qual será dirigida à ouvidoria do órgão ou entidade responsável e conterá a identificação do requerente (art. 10), devendo a ouvidoria encaminhar a decisão administrativa final ao usuário, no prazo de trinta dias, prorrogável por igual período, de forma justificada e por uma única vez (art. 16).

O Decreto 9.492/2018, que regulamenta a Lei 13.460/2017, instituiu o Sistema de Ouvidoria do Poder Executivo federal, integrando, como órgão central, o Ministério da Transparência e Controladoria-Geral da União, por meio da Ouvidoria-Geral da União, e como unidades setoriais, as ouvidoria dos órgãos e das entidades da administração federal abrangidos pelo próprio Decreto, tendo como objetivos (art. $5^{\circ}$ ): coordenar e articular as atividades de ouvidoria a que se refere este Decreto; propor e coordenar ações com vistas a desenvolver o controle social dos usuários sobre a prestação de serviços públicos, e facilitar o acesso do usuário de serviços públicos aos instrumentos de participação na gestão e na defesa de seus 
direitos; zelar pela interlocução efetiva entre o usuário de serviços públicos e os órgãos e as entidades da administração pública federal responsáveis por esses serviços; e acompanhar a implementação da Carta de Serviços ao Usuário de que trata o art. $7^{\circ}$ da Lei 13.460/2017, de acordo com os procedimentos adotados pelo Decreto 9.094/2017.

A Ouvidoria-Geral da União está ligada ao Ministério da Transparência e Controladoria-Geral da União (CGU), sendo responsável "por receber, examinar e encaminhar denúncias, reclamações, elogios, sugestões e pedidos de informação referentes a procedimentos e ações de agentes, órgãos e entidades do Poder Executivo Federal" (CONTROLADORIA-GERAL, s.d.).

Atualmente, o instituto do Ombudsman, apesar da inaplicabilidade do termo de forma expressa na legislação, é uma realidade no Brasil, normalmente denominado de Ouvidoria, sendo diversas as entidades que o exercem, havendo, inclusive, uma Associação Nacional e variadas associações estaduais a seu respeito, como ocorre no Estado de São Paulo.

\section{CONCEITO E IMPORTÂNCIA DO OMBUDSMAN}

A palavra Ombudsman é de origem germânica, e significa "aquele que faz o trâmite" ou "o intermediário". É conhecido por ser o ouvidor do povo, que não se limita somente a ouvir, mas a solucionar problemas relacionados à Administração Púbica. O Ombudsman é um órgão independente da Administração Pública. É dotado de independência funcional para fiscalizar a atuação dos servidores públicos (BEZERRA, 2010).

De acordo com Antonio Rovira Viñas (2002, p. 67):

Por eso es necessário el ombudsman, porque em las sociedades democráticas avanzadas cada día se necesitan más instancias com autoridade que limiten y controlen esta tendência omnicomprensiva del poder, que aunque constitucionalmente dividida, está muy concertrada, y ésta puede ser uma de las razones para explicar la actualidad y su auge en el mundo 4 .

Segundo Catarina Sampaio Ventura (2008, p. 34), o "Ombudsman é definido como um órgão público (tendencialmente unipessoal) independente e imparcial, tendo na base da sua criação, em regra, um ato legislativo parlamentar". É instituído como mecanismo de controle da Administração Pública, de modo a zelar pela legalidade e justiça dos comportamentos administrativos. Para Jorge Carlos Fonseca (2000), o Ombudsman pauta-se pela informalidade, no que a previsão deste órgão contribui de modo decisivo para o reforço da proteção dos cidadãos, ao implantar mecanismos de proteção jurídica prevista na Constituição ou na lei.

A respeito do Ombudsman, assevera Celso Barroso Leite (1975, p. 64) que, "sendo este, um instrumento de defesa do povo contra a Administração Pública, está se colocando frente ao administrado, em benefício de ambos, tanto protegendo o cidadão contra investidas públicas, quanto, defendendo o cumprimento legal de sua atividade".

4 Tradução nossa: "Por isso é necessário o Ombudsman, Porque as sociedades avançadas democráticas precisam cada dia mais de instâncias com autoridade que limitam e controlam a tendência de omissão do poder, que embora constitucionalmente dividida, está muito concentrada, e esta pode ser uma das razões para explicar na atualidade o seu bem para o mundo". 
Nos Estados que adotam o instituto jurídico-administrativo do Ombudsman, "sobreleva sua máxima função, consistente em prevenir e preencher lacunas e omissões de outros tipos de controle administrativo e/ou judiciário, atinente aos três Poderes, sobretudo ao Poder Executivo (Administração Pública)" (GUALAZZI, 1991, p. 146).

Ana Fernanda Neves (2005) relata que a instituição do Ombudsman assegura a cada cidadão a certeza do poder de viver em condições de liberdade e de segurança, na medida em que, com total independência, ele censura e controla os erros, excessos e abusos dos poderes constituídos.

De acordo com Gustavo Costa Nassif (2010), Ouvidor de Fazenda, Patrimônio e Licitações Públicas do Estado de Minas Gerais, os Ouvidores/Ombudsman são os responsáveis pelas críticas construtivas dentro das entidades e corporações, atuando na defesa dos direitos dos cidadãos/consumidores, recebendo e investigando queixas e denúncias relativas à qualidade dos serviços prestados pelo poder público ou pelas empresas privadas e, após fazer o filtro das informações, irá recomendar e influenciar os setores envolvidos a tomarem medidas para a promoção da correção das disfunções.

Catarina Sampaio Ventura (2008, p. 101) destaca a dualidade de modelos de Ombudsman, nos seguintes termos:

Delineando dois modelos tendenciais do Ombudsman - um voltado para o Estado de direito e a boa administração, outro centrado na proteção e promoção dos direitos humanos - e sugerida enfim, uma delusória tensão entre ambos, no que à matéria da proteção dos direitos humanos concerne, sem prejuízo da delimitação, mais estreita num caso, mais amplo, em outro, da respectiva função, debrucemo-nos, agora sobre algumas das dimensões possíveis de relevância dos direitos humanos na atividade do Ombudsman, incluindo as instituições que se aproximam mais do modelo clássico de vigilância estrita administrativa dos poderes públicos. [...]. O Ombudsman, tutela pelos direitos humanos, a defesa da ordem social, e a democracia popular.

Desde a antiga democracia grega, "passando pela escandinava do século XIX, chegando finalmente às democracias modernas, fica evidente a importância do Ombudsman ou Ouvidor para o aperfeiçoamento do sistema político, produzindo o máximo de satisfação para o maior número de cidadãos" (FERRES, 2019, p. 53).

Importante destacar que a Ouvidoria é um dos canais mais importantes para o exercício da participação popular e para o controle social em prol dos cidadãos e da proteção dos direitos do indivíduo (BASTOS; PEREIRA, 2029, p. 34).

O Ombudsman, na essência, dotado de independência funcional, atua como ente fiscalizador da Administração Pública, com especial ênfase na proteção dos direitos fundamentais e da própria democracia. 


\section{3. ÂMBITO DE ATUAÇÁO DO OMBUDSMAN OU DEFENSOR DO POVO}

A competência do defensor do povo deve ser a mais ampla possível, podendo até mesmo agir de ofício, sobre qualquer assunto relativo à administração civil do país, que julgue de interesse a ser investigado (AMARAL FILHO, 1993, p. 128).

Para a Controladoria-Geral da União, enquanto a ouvidoria é um espaço em que se pode apresentar sugestões, elogios, solicitações, reclamações e denúncias, a ouvidoria pública "atua no diálogo entre o cidadão e a Administração Pública, de modo que as manifestações decorrentes do exercício da cidadania provoquem contínua melhoria dos serviços públicos prestados" (CONTROLADORIA-GERAL, s.d.).

Intervindo com base em queixas dos cidadãos ou por sua própria iniciativa, o âmbito de atuação do Ombudsman abrange, regra geral, a função administrativa do Estado. Todavia, está fora da sua alçada o controle do exercício dos poderes políticos, legislativos e judiciário (VENTURA, 2008, p. 34).

Francisco Ferreira de Almeida (2003, p. 31) complementa:

O Ombudsman, não tem, por conseguinte, poder para modificar, revogar, ou anular os atos dos poderes públicos. [...]. Fica estrito ao seu comportamento, os casos trazidos à sua apreciação, ou que ele próprio, entenda que deve analisar. [...] Ombudsman "quem vigia o vigilante".

Assim, no tocante a seu âmbito de atuação, o Ombudsman encontra-se limitado ao controle da Administração Pública e deve apresentar relatórios anuais, sobretudo a fim de trazer ao conhecimento e juízo públicos os comportamentos que suscitaram a intervenção. De tal forma, os relatórios do Ombudsman assumem importante função de proporcionar o exame e análise do estado da Administração (VENTURA, 2008, p. 38).

Todavia, para Marcos Jordão Teixeira de Amaral Filho (1993, p. 121):

embora a competência do Ombudsman não possa atingir as atividades desenvolvidas pelo Congresso Nacional e por seus membros no exercício de suas funções, o defensor do povo deverá igualmente ter a prerrogativa de investigação quando um deputado ou senador estiver exercendo funções no âmbito da administração, inclusive em funções ministeriais.

Para garantir o bom funcionamento do Ombudsman, deve-se assegurar e garantir o êxito de suas funções, entre as quais se destacam (AMARAL FILHO, 1993, p. 127): acesso direto de todo cidadão, sem intermediação de parlamentares; acesso a todos os documentos necessários à investigação, inclusive com possibilidade de convocar funcionários para depoimento e testemunhas; motivação simples de sua decisão e encaminhamento rápido à autoridade competente para providências; em caso de resistência da autoridade, possibilidade de oferecer denúncia contra o funcionário ou solicitar à autoridade hierárquica superior que modifique a decisão.

Ana Fernanda Neves (2005) explica que o Ombudsman, com ou sem aviso prévio, visita as instalações de todo setor da Administração Pública, objetivando assegurar que todas as atividades estão sendo realizadas com o devido zelo e diretrizes de seu funcionamento. 
Em conformidade com o art. $2^{\circ}$ do Estatuto da Associação Brasileira de Ouvidores/ Ombudsman - ABO, de caráter nacional, a Associação tem por objetivo, entre outros, estimular e promover o congraçamento e o relacionamento entre todos aqueles que exerçam a função de Ouvidor/Ombudsman no Brasil. O ouvidor/ombudsman, por sua vez, tem como dever defender os direitos e os legítimos interesses dos cidadãos, seja em órgãos da administração pública de qualquer nível ou poder, seja em uma empresa privada, "atuando, sempre, com autonomia para apurar as questões que lhe forem apresentadas e independência para manifestar o que entender cabível à instituição a qual é vinculado" (ABO NACIONAL, 1995).

\section{IMPLANTAÇÁO DO OMBUDSMAN NO BRASIL}

A Assembleia Nacional Constituinte Brasileira rejeitou a emenda da deputada Raquel Capiberibe, do PMDB do Amapá, que propunha a criação do defensor do povo ou Ombudsman no Brasil. Para Hugo Nigro Mazzilli (2007), o defensor do povo constava do Anteprojeto da Constituição de 1986, indicado pelo Senador Afonso Arinos. O Ombudsman seria escoIhido pela Câmara dos Deputados, dentre os candidatos indicados pela população.

Segundo Marcos Jordão Teixeira de Amaral Filho (1993), levantaram-se poderosos lobbies corporativos contra sua criação, como os do Tribunal de Contas da União e do Ministério Público. Ainda, a pressão exercida por setores da opinião pública e a experiência do Conselho de Defesa dos Direitos do Cidadão e do ouvidor-geral curitibano não foram suficientes para o convencimento dos constituintes, muitos dos quais egressos do próprio Ministério Público ou identificados de alguma forma com os interesses da Administração.

Wallace Paiva Martins Júnior (2002, p. 78) complementa que foi preferido atribuir as funções de Ombudsman ao Ministério Público, que já estava presente em todo território brasileiro, do que criar um novo órgão.

Segundo Cândido Mendes (1987, p. 3):

SUMIU NA PROPOSTA CONSTITUINTE A FIGURA DO DEFENSOR DO POVO, TRANSFERINDO-SE PARA O MINISTÉRIO PÚBLICO A TAREFA DE ESCRUTINAR E PROMOVER A RESPONSABILIDADE DO ABUSO DE PODER DE QUALQUER GOVERNO. [...]. NADA SE DIZ SOBRE O PIOR DELES QUE É, EXATAMENTE, A OMISSÃO DAS AUTORIDADES PÚBLICAS PROTRAIIDAS CADA VEZ MAIS NA INERCIA BUROCRÁTICA, PRESAS À SUA ESTRITA E IMEDIATA DINÂMICA DE INTERESSES. [...]. AINDA É TEMPO DE VOLTARMOS AO DEFENSOR DO POVO. SEM CARREIRAS NEM MORDOMIAS NEM REELEIÇÕES.

A Constituição Federal de 1988 estatui que o "Poder Legislativo é exercido pelo Congresso Nacional, que se compõe da Câmara dos Deputados e do Senado Federal" (art. 44). Entre as atribuições do Congresso Nacional, delimitadas na Seção II do Título IV, Capítulo I, está a possibilidade de convocação do Presidente da República e de seus Ministros de Estado, para prestarem pessoalmente informações, em assunto previamente determinado, importando a ausência, sem justificação adequada, em crime de responsabilidade (art. 50). Ainda, compete privativamente à Câmara dos Deputados, nos termos do art. 51, "autorizar, por dois terços de seus membros, a instauração de processo contra o presidente da Repú- 
blica e os ministros de Estado" (inciso I) e "proceder à tomada de contas do presidente da República, quando são apresentadas ao Congresso Nacional dentro de sessenta dias após a abertura da sessão legislativa" (inciso II). O Congresso Nacional poderá constituir comissões permanentes e temporárias, cabendo a elas, nos termos do art. $58, \S 2^{\circ}$, "convocar ministros de Estado para prestar informações sobre assuntos inerentes às suas atribuições" (inciso III) e "receber petições, reclamações ou queixas de qualquer pessoa contra atos ou omissões das autoridades ou entidades públicas" (inciso V) (BRASIL, 1988).

Percebe-se que, apesar do Congresso Nacional não dispor de responsabilidade de governo, já que foi mantido o sistema presidencialista pelo Constituinte de 1988, houve ampliação de sua ação de controle político sobre os ministros e o chefe de governo.

Marcos Jordão Teixeira de Amaral Filho (1993, p. 119) já asseverava que a introdução do direito de petição aos cidadãos contra atos ou omissões das autoridades ou entidades públicas revelava também a preocupação dos nossos constituintes com a preservação dos direitos individuais, função esta tradicionalmente delegada ao Ombudsman.

Nesse ponto, a criação do Defensor do Povo deve levar em conta a nova realidade constitucional brasileira, e seria de todo conveniente, a fim de evitar conflito de atribuições entre o Parlamento e o Ombudsman, que o controle do Presidente da República e de seus ministros, em razão do caráter mais político de suas funções, ficasse restrito à atuação do Congresso Nacional, ou que o Ombudsman pudesse agir, em virtude de provocação do próprio Congresso Nacional, pois seu papel é em função do povo e da democracia (BEZERRA, 2010).

Importante ressaltar que o Ombudsman, na concepção de Wallace Paiva Martins Júnior (2002), não tem atribuição administrativa nem jurisdicional, sendo essa a razão para não intervir no Poder Judiciário. Tem competência somente para verificar a legalidade e a legitimidade do ato administrativo, e recomendar sua invalidação no caso de nulidade, ou revogação em razão de conveniência ou oportunidade.

O Ombudsman também possui relação com as Comissões Parlamentares de Inquérito.

O Brasil adotou a forma de governo presidencialista, inspirada no modelo norte-americano, que veio a conhecer as tradicionais comissões parlamentares de inquérito como forma de controle parlamentar. Todavia, apesar dos méritos indiscutíveis de algumas destas comissões em seu trabalho fiscalizador, as mesmas estão condicionadas às maiorias parlamentares, nem sempre dispostas à sua criação, e não podem se ocupar de casos individuais, uma vez que devem estar voltadas a temas de caráter mais geral da administração. Dessa forma, o defensor do povo tem amplo campo de atuação fiscalizadora, sem retirar do Parlamento suas prerrogativas fiscalizadoras tradicionais, inclusive dando-lhe status mais elevado no exercício de sua atividade (AMARAL FILHO, 1993, p.124).

Como visto, embora a Constituição Federal de 1988 não tenha previsto expressamente a figura do Ombudsman com essa nomenclatura, o instituto é uma realidade no País, estando previsto em diversos diplomas normativos infraconstitucionais, sob a denominação genérica de Ouvidoria. 


\section{OMBUDSMAN, TRIBUNAL DE CONTAS DA UNIÃO, PODER EXECUTIVO, MINISTÉRIO PÚBLICO E PODER JUDICIÁRIO}

A Constituição Federal estabelece no art. 71 que o "controle externo, a cargo do Congresso Nacional, será exercido com o auxílio do Tribunal de Contas da União, ao qual compete" (BRASIL, 1988).

0 art. $71, \S 4^{\circ}$, da Lei Maior, determina que "o tribunal encaminhará ao Congresso Nacional, trimestral e anualmente, relatório de suas atividades". Já o art. $74, \S 2^{\circ}$, da Constituição, estatui que "qualquer cidadão, partido político, associação ou sindicato" é parte legitima para, na forma da lei, denunciar irregularidades ou ilegalidades perante o Tribunal de Contas da União (BRASIL, 1988).

Marcos Jordão Teixeira de Amaral Filho (1993, p. 123) analisa que os Constituintes de 1988 ampliaram de forma nítida o rol de competências do Tribunal de Contas da União, que decididamente deixa de ser mera Corte de Contas e passa à condição de fiscal do Poder Público, com grandes semelhanças em relação às atribuições clássicas do Ombudsman.

Realmente, é indiscutível que o espaço de atuação de um Ombudsman no Brasil ficou severamente restringido pela redação da Constituição Federal de 1988 no que tange às competências do Tribunal de Contas da União. A sobrecarga de trabalho que disto resultará sobre o Tribunal pode levar futuramente a se pensar em novo desdobramento de funções, voltando nossa Corte de Contas às suas atribuições clássicas e delegando ao defensor do povo (Ombudsman) a fiscalização de atos da administração que violem os direitos individuais ou de grupos, com o objetivo indireto de se proteger a ordem democrática (AMARAL FILHO, 1993, p. 123).

De acordo com Helga Maria Saboia Bezerra (2010), na condição atual seria necessária a revisão do texto constitucional para se evitar um possível conflito de atribuições entre o Tribunal de Contas da União e o Ombudsman.

No Brasil, ao contrário da Suécia, os Ministros de Estado são responsáveis pelos atos de seus subordinados, numa relação hierárquica que se estabelece dos mais baixos escaIões até o Presidente da República. De tal modo, com essa estrutura administrativa seria impensável que um Ombudsman não pudesse fiscalizar os atos administrativos dos ministros de Estado, que concentram vasta competência no âmbito administrativo. Já no caso da Noruega (AMARAL FILHO, 1993, p. 125):

atribuiu-se ao Ombudsman a faculdade de apreciar aspectos discricionários da ação administrativa. No Brasil, que possui administração fortemente marcada por traços autoritários, seria conveniente, da mesma forma, que coubesse ao defensor tal competência, em que ações administrativas, embora intentadas dentro da legalidade existente, fugisse aos princípios da razoabilidade e equidade com o administrado exigidos pelo bom Direito Administrativo.

Para Francisco Ferreira de Almeida (2003), seria inconveniente que o defensor do povo pudesse intervir nos assuntos presidenciais, mesmo assim, nos casos em que a lei determinar ou naqueles atos em que o Presidente tenha agido tão somente na qualidade de superior 
hierárquico da Administração, deve o Ombudsman do povo ter competência para agir, preservando sempre a figura institucional da Presidência da República.

Todavia, há quem sustente na doutrina que no Brasil a função do Ombudsman é exercida pelo Ministério Público.

Assim, de acordo com Hugo Nigro Mazzilli (2007), o texto constitucional destinou ao Ministério Público a função de Ombudsman, de zelar pelos interesses sociais e individuais, não tendo vinculação hierárquica com os poderes do Estado.

Segundo Ana Fernanda Neves (2005), cabe ao Ministério Público a defesa da ordem jurídica, do regime democrático e dos interesses sociais e individuais.

Na Suécia, o Ombudsman possui competência semelhante à do Ministério Público Brasileiro. Porém, como antes afirmado, a rejeição do Plenário da Assembleia Nacional Constituinte à criação do Defensor do Povo deu-se em grande parte em razão das pressões exercidas pelos procuradores ligados ao Ministério Público, que viam na sua criação uma possível limitação às suas funções.

Conforme Cândido Mendes (1987, p. 3):

Desperdiçamos a oportunidade de aproveitar o exemplo espanhol e acautelar-se a sociedade civil contra o Estado através de uma Defensoria do Povo para denunciar e processar abusos de poder, por fora da corporação governamental. Não demos o passo decisivo: a tarefa continua dentro da competência do Ministério Público.

Para María José Colchete Martín (2001), o chefe do Ministério Público não deveria ser escolhido pelo Poder Executivo. Nesse ponto, o Ombudsman europeu é indicado pelo Parlamento, órgão que tem atribuição de fiscalizar o Poder Executivo.

Sob outro ângulo, de se observar que o Poder Judiciário não está sujeito à fiscalização pelo Ombudsman.

Nesse sentido, durante os trabalhos da Assembleia Nacional Constituinte, especialmente na apreciação do capítulo que tratava da organização do Poder Judiciário, uma grande polêmica estabeleceu-se em torno da criação do Conselho Nacional de Justiça para exercer controle externo sobre a magistratura. Todavia, o Plenário Constituinte optou por preservar inteiramente a independência do Poder Judiciário.

No Brasil, sem ferir a independência do Poder Judiciário, seria interessante um controle restrito ao seguimento dos processos e ao cumprimento dos ritos processuais, que recuperasse a confiança da sociedade, especialmente nos casos da administração judiciária, no tocante à execução das penas criminais, que caberia ao Ombudsman, como instrumento importante de diálogo com os detentos. Não se admitiria nenhuma ação que envolvesse decisão judicial ou ato praticado no exercício de suas prerrogativas, que pudesse prejudicar a relação entre o defensor do povo e o Poder Judiciário, ou de algum modo limitar a independência do magistrado (AMARAL FILHO, 1993, p.127).

Todavia, embora não previsto na redação originária da Constituição Federal, o ConseIho Nacional de Justiça (CNJ), acabou sendo criado por meio da EC 45/2004, que incluiu o art. 103B no texto constitucional, competindo-Ihe, nos termos do $\S 4^{\circ}$ do referido art. 103,0 controle da atuação administrativa e financeira do Poder Judiciário e do cumprimento dos 
deveres funcionais dos juízes, cabendo-Ihe o exercício de diversas atribuições previstas no bojo do próprio art. 103, além de outras atribuições que Ihe forem conferidas pelo Estatuto da Magistratura.

\section{CONCLUSÃO}

O Ombudsman, também conhecido atualmente como Provedor de Justiça, Defensor do Povo ou Ouvidor, surgiu na Suécia em 1809, dando origem e influenciando a implementação do instituto em diversos países, como Finlândia, Noruega, Alemanha, Dinamarca, Grã-Bretanha e Portugal.

Embora o termo Ombudsman não seja utilizado de forma expressa na legislação brasileira, na prática é uma realidade no País, normalmente com o nome de Ouvidoria, sendo várias as entidades que se valem concretamente do instituto, como a Associação Brasileira de Ouvidores/Ombudsman, de caráter nacional, e a Associação Brasileira de Ouvidores/ Ombudsman do Estado de São Paulo.

A figura do Ombudsman ou Ouvidor, desde seu advento, ganhou respeitabilidade, sendo atualmente bastante importante para o aperfeiçoamento do sistema político e para a satisfação dos interesses e direitos dos cidadãos, inclusive no que se refere ao controle das atividades exercidas pela Administração Pública.

O defensor do povo, por qualidades que se confirmaram em diversos ordenamentos jurídicos estrangeiros, possibilita a busca de promoção dos direitos fundamentais e contribui para o controle das atividades de responsabilidade do Estado, em especial as relacionadas à atuação administrativa.

A morosidade dos processos administrativos, o controle jurisdicional inadequado e a necessidade de uma fiscalização imparcial sobre a atividade estatal, são razões para a criação do Ombudsman no Brasil.

Nesse contexto, e como instrumento de exercício da democracia, a criação do Ombudsman poderia suprir eventuais deficiências institucionais dos órgãos de controle atualmente existentes no País, como o Ministério Público e os Tribunais de Contas.

Pelas características brasileiras e pela experiência de outros países, é conveniente que a criação do Ombudsman ou Defensor do Povo seja feita preferencialmente pela via constitucional, evitando-se com isso sua fragilização por meio de interferências normativas infraconstitucionais.

O sucesso do Ombudsman no Brasil está diretamente relacionado à abertura democrática e à participação política dos indivíduos e da própria sociedade, podendo o instituto tornar-se um importante canal voltado para a resolução de conflitos entre os cidadãos e entre estes e o próprio Estado.

O Ombudsman, como órgão de controle externo, contribui para a fiscalização imparcial do exercício das atividades e funções inerentes aos Poderes Públicos. 
Tem-se, em conclusão, que restou demonstrada a hipótese inicial, no sentido de que o Ombudsman, embora o termo não esteja previsto expressamente na legislação brasileira, deve ser implantado no Brasil, objetivando fiscalizar o exercício das atividades do Poder Executivo, em especial atuando como guardião da legalidade e contra os abusos de poder praticados pela Administração Pública.

\section{REFERENNCIAS}

ABO NACIONAL - Associação Brasileira de Ouvidores/Ombudsman. Estatuto Social. 1995. Disponível em: http:// www.abonacional.org.br/estatuto. Acesso em: 12 abr. 2019.

ABO SÃO PAULO - Associação Brasileira de Ouvidores/Ombudsman - São Paulo - s.d. Disponível em: http:// www.abosaopaulo.org.br/artigo.php?codigo=15. Acesso em: 16 jan. 2019.

ALMEIDA, Francisco Ferreira de. Direito internacional público. 2. ed. Coimbra: Coimbra Editora, 2003.

AMARAL FILHO, Marcos Jordão Teixeira de. O Ombudsman e o controle da Administração. São Paulo: Edusp, 1993.

BASTOS, Camila Sanson Pereira; PEREIRA, Carolina de Lima Cazarotto. O fortalecimento das ouvidorias como instrumento de controle social: análise e impactos para a aplicação da Lei 13.460/2017. Revista Científica da Associação Brasileira de Ouvidores/Ombudsman, São Paulo, ano 2, n. 2, p. 31-39, 2019.

BEZERRA, Helga Maria Saboia. Defensor do povo: origens do instituto do Ombudsman e a malograda experiência brasileira. Revista Direito, Estado e Sociedade, Rio de Janeiro, n. 36, p. 46-73, jan./jun. 2010.

BRASIL. Constituição (1988). Constituição da República Federativa do Brasil. Disponível em: http://www.planalto. gov.br/ccivil_03/Constituicao/ConstituicaoCompilado.htm. Acesso em: 31 out. 2018.

CONTROLADORIA-GERAL DA UNIÃO. Ouvidoria. Disponível em: http://www.cgu.gov.br/assuntos/ouvidoria. Acesso em 22 jan. 2019.

FERRES, Dionisio Moreno. A evolução histórica das ouvidorias: da participação reividicatória por melhorias nas políticas públicas ao empowerment dos cidadãos. Revista Científica da Associação Brasileira de Ouvidores/ Ombudsman, São Paulo, ano 2, n. 2, p. 41-54, 2019.

FONSECA, Jorge Carlos. Estado de direito democrático, direitos fundamentais e o instituto do Ombudsman - uma introdução ao tema: Ombudsman - quadro normativo e experiência institucional. Direito e cidadania, Lisboa, ano III, n. 8, p. 109-122, 2000

GELLHORN, Walter. Ombudsmen and others: citizen's protectors in nine countries. London: Harvard University Press, 1966.

GUALAZZI, Eduardo Lobo Botelho. Controle administrativo e "ombudsman". Revista da Faculdade de Direito, Universidade de São Paulo, v. 86, p. 144-163, 1991.

LEITE, Celso Barroso. Corregedor administrativo: a instituição escandinava que o mundo vem adotando. Rio de Janeiro: Zahar, 1975.

MARTÍN, María José Corchete. El defensor del pueblo y la protección de los derechos. Salamanca: Ediociones Universidad de Salamanca, 2001.

MARTINS JÚNIOR, Wallace Paiva. Controle da administração pública pelo Ministério Público: Ministério Público defensor do povo. São Paulo: Juarez de Oliveira, 2002.

MAZZILLI, Hugo Nigro. O acesso à justiça e o Ministério Público. 5. ed. São Paulo: Saraiva, 2007.

MENDES, Cândido. O gato comeu o defensor do povo. Folha de São Paulo, São Paulo, 24 nov. 1987, p. 3. 
NASSIF, Gustavo Costa. Ouvidor ou Ombudsman? Jornal Carta Forense. 2010. Disponível em: http://www.cartaforense.com.br/conteudo/artigos/ouvidor-ou-ombudsman/5766. Acesso em 16 jan. 2019.

NEVES, Ana Fernanda. O provedor de justiça e administração pública. In: MIRANDA, Jorge (Coord.). Estudos em homenagem ao Prof. Doutor Joaquim Moreira da Silva Cunha. Coimbra: Coimbra Editora, 2005, p. 51-92.

REMEDIO, José Antonio; FARIA, Cássio Henrique Dolce de. Convenção da Apostila de Haia: incorporação e integração ao ordenamento jurídico nacional e interface com os direitos fundamentais. Meritum, Belo Horizonte, v. 14, n. 2. p. 708-726, jul./dez. 2019.

ROVIRA VIÑAS, Antonio (Org.). Comentarios a la Ley Orgánica del Defensor del Pueblo. Navarra: Editorial Aranzadi, 2002.

SILVA. Wanderlei Batista. Considerações sobre a ouvidoria. s.d. Disponível em: http://mpprmmp.br/pagina3.html. Acesso em: 2 out. 2018.

UNIVERSIDADE FEDERAL DE GOIÁS - UFG. Ouvidoria. s.d. Disponível em: https://ouvidoria.ufg.br/n/29881-ombudsman-o-que-e-o-cargo. Acesso em: 12 abr. 2019.

VENTURA, Catarina Sampaio. Direitos humanos e ombudsman: paradigma para uma instituição secular. Lisboa: Provedoria de Justiça, 2007.

Recebido/Received: 02.05.2019.

Aprovado/Approved: 04.07.2020. 